\title{
Novel object exploration in ravens (Corvus corax): Effects of social relationships
}

\author{
Mareike Stöwe $^{\mathrm{a}, *}$, Thomas Bugnyar ${ }^{\mathrm{a}, \mathrm{b}}$, Matthias-Claudio Loretto ${ }^{\mathrm{a}}$, \\ Christian Schloegl ${ }^{\mathrm{a}}$, Friederike Range ${ }^{\mathrm{b}}$, Kurt Kotrschal $^{\mathrm{a}, \mathrm{b}}$

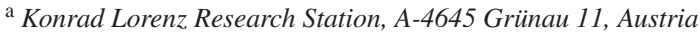 \\ ${ }^{\mathrm{b}}$ Department for Behaviour, Neurobiology and Cognition, University of Vienna, Althanstrasse 14, 1090 Vienna, Austria
}

\begin{abstract}
Social context has been shown to encourage, or to delay object exploration and learning. This ambiguity might be due to factors such as social relationships and personality of the individuals involved. Here, we investigated in ravens (Corvus corax) individuals' consistency in response to novel objects over development and across contexts: alone versus social. In the social setting we focussed on the effects of social relationships on social facilitation during the approach to novel objects. We tested 11 hand-raised ravens with novel objects individually at three and six months of age and in dyadic combinations at six months of age. Individuals were consistent over development and contexts in their response to different novel objects. Birds joined siblings faster to approach novel objects than non-siblings. They also spent more time sitting close to siblings than to non-siblings. In male-male dyads but not in female-female dyads, subordinates approached the novel objects significantly faster than dominant birds. In contrast, dominant males were the first to approach the novel objects in mixed-sex combinations. Hence, the effect of social context seems to depend on the social relationships towards the companions and on the combination of the sexes.
\end{abstract}

Keywords: Corvus corax; Neophobia; Social facilitation; Social relationship

\section{Introduction}

The presence of a conspecific has often been shown to facilitate exploration and learning. The acceptance of novel food, for example, was facilitated by the presence or action (handling or food intake) of a conspecific in gerbils (Meriones unguiculatus: Forkman, 1991), zebra finches (Taeniopygia guttata: Coleman and Mellgren, 1994), capuchin monkeys (Cebus apella: Visalberghi and Fragaszy, 1995; Visalberghi and Addessi, 2000), rats (Rattus norvegicus: Galef, 1996; Galef and Whiskin, 2000), keas (Nestor notabilis: Huber et al., 2001) and house mice (Mus musculus domesticus: Valsecchi et al., 2002). Other studies showed that observers learned better when demonstrators were dominant (red-winged blackbirds, Agelaius

\footnotetext{
* Corresponding author. Tel.: +43 664 4541904/761 68510; fax: +43761685104

E-mail addresses: klf.gruenau@telecom.at, m_stoewe@ hotmail.com (M. Stöwe)
}

phoeniceus: Mason and Reidinger, 1981; jackdaws, Corvus monedula: Katzir, 1983; laying hens, Gallus gallus domesticus: Nicol and Pope, 1994, 1999). Also, familiarity had a facilitating effect (guppys, Poecilia reticulata: Swaney et al., 2001; zebra finches, T. guttata: Benskin et al., 2002), particularly in the case of parent-infant or adult-infant combinations (e.g. Fragaszy and Visalberghi, 1996; Fritz et al., 2000; Brown et al., 2004). On the other hand, delay and inhibition of approach/acceptance of novel food in a social context have been observed in chum salmon, Oncorhynchus keta (Ryer and Olla, 1991), atlantic salmon, Salmo salar (Brown and Laland, 2001, 2002) and great tits, Parus major (van Oers et al., 2005).

An important factor contributing to these contrasting results may be the quality of social relationships (affiliative or not). Affiliative relationships may increase the possibility of scrounging (gaining food via others; Barnard and Sibly, 1981), for example, begging or food sharing. Profitability of scrounging, seems to influence whether social context facilitates or delays social learning (Giraldeau and Lefebvre, 1987; Fritz and Kotrschal, 1999, 2002; Midford et al., 2000; Caldwell and Whiten, 2003; 
Visalberghi and Addessi, 2003). Hence, the quality of social relationships may determine whether social context facilitates or delays exploration.

Finally, the combination of individuals with certain behavioural phenotypes might also modulate the effect of social context on approach to novel food/objects. Individuals differ in suites of correlated behavioural and physiological parameters ("coping styles") leading to a cross-context consistency how they deal with challenges (Koolhaas et al., 1999; Sih et al., 2004; Groothuis and Carere, 2005). Exploratory behaviour correlates with aggressiveness (Verbeek et al., 1996; Drent and Marchetti, 1999), boldness (Verbeek et al., 1994), risk taking (van Oers et al., 2004, 2005), feeding behaviour (Coleman and Wilson, 1998; Marchetti and Drent, 2000) and the capability of coping with social defeat (von Holst, 1998; Carere et al., 2001, 2003). Such individual differences in behavioural phenotypes are genetically and epigenetically heritable (Dingemanse et al., 2002; Drent et al., 2003; Daisley et al., 2004; van Oers et al., 2004) and may affect dispersal (Armitage, 1986; Dingemanse et al., 2003), dominance (Gómez-Laplaza, 2002; Dingemanse and de Goede, 2004), mate choice, survival (Cavigelli and McClintock, 2003) and reproductive success (Dingemanse et al., 2004; Both et al., 2005).

Ravens are scavengers on ephemeral food sources, such as carcasses, garbage dumps, etc. After becoming independent from their parents in their first summer, they assemble in non-breeder groups (Glutz von Blotzheim and Bauer, 1993; Ratcliffe, 1997). Ravens are curious and highly exploratory but when older than one month post-fledging they fear almost anything new (Heinrich, 1988a, 1995; Heinrich et al., 1995; Kijne and Kotrschal, 2002). Neophobia limits explorative behaviour and may constrain exploitation of novel food sources, learning and innovation (Kotrschal et al., 2001; Seferta et al., 2001; Greenberg, 2003; Reader and Laland, 2003). Conspecifics (Marzluff and Heinrich, 1991), birds and mammals (e.g. wild boars, Sus scrofa, crows, Corvus corone corone, Corvus corone cornix: own observation; wolves, Canis lupus: Promberger, 1992; Bugnyar and Kotrschal, 2001; Stahler et al., 2002) may have facilitating effects on ravens' approach to food sources. In addition, ravens recruit conspecifics at food bonanzas emitting a specific call (Heinrich, 1988b, 1994; Heinrich and Marzluff, 1991, 1995; Marzluff et al., 1996; Bugnyar et al., 2001).

Here, we investigated whether individual patterns in exploratory behaviour remain consistent over development (at three and six months of age) and context: alone versus in dyadic combination with a conspecific. In the latter situation, we were interested whether the quality of social relationships affected (joint) approach to novel objects. According to biological personality theory, we expected individual consistency in exploratory behaviour over both, development and contexts, such that individuals remain fast/slow in relation to the others. We finally expected that joint approach to novel objects will covary with the quality of dyadic social relationships. Hence, in dyads showing high rates of socio-positive behaviour, individuals would join each other in approach and manipulation of the novel objects.

\section{Materials and methods}

\subsection{Animals and housing}

In spring 2004, we hand-raised a group of 13 ravens ( 7 males and 6 females) under standardised conditions. The birds were habituated to close contact with people. Ravens of two nests (containing four and three ravens, respectively) were zoo-bred, birds of the two other nests (containing three ravens each, one nest of three siblings, one nest with three non-siblings) were taken from the wild with permission. We kept the birds in nests together (see above) in an indoor aviary. Just before fledging we transferred all the birds into one big nest in an outdoor aviary where they remained thereafter. Once fledged, we kept them together in one group with two previously raised adult males (nine and four years of age). Birds were marked with coloured leg rings for individual identification. The aviary was divided into three sections separated by wire mesh $(80,35$ and $80 \mathrm{~m}^{2}$ ) and in addition had three experimental rooms, separated by wooden walls and opaque doors. Aviaries contained trees, branches, stones, tree trunks and shallow pools for bathing. The floor was natural grass ground in the main compartments, but gravel in the experimental rooms. Experiments were conducted in one of the large compartments $\left(80 \mathrm{~m}^{2}\right)$ in physical and visual, but not acoustical isolation from the rest of the group. Birds were fully habituated to short separations from the group as it was a standard procedure in previous experiments. The ravens were fed twice a day (in the mornings and afternoons after the experiments) with meat, milk products and kitchen leftovers. Water was provided ad libitum.

\subsection{Experimental set-up}

We conducted novel object tests with the juveniles only, since the pre-experience with objects was similar in all juveniles but not in the adult birds. Altogether, we conducted three sets of novel object tests.

\subsubsection{Alone condition}

We performed two series of novel object tests per bird in the alone condition. The first series of four tests was carried out from mid-June (with the birds being three months of age, approximately seven weeks post-fledging) until the end of July. The second series of four novel object tests was performed from the beginning of September, when the young ravens were six months old, to the beginning of November. If raised by their parents, the juveniles would still have been dependent on them during our first test series, but independent during the second series.

\subsubsection{Dyadic condition}

The tests were conducted at the same time as the second series of novel object tasks in the alone condition. Tests were alternated between the alone and the dyadic condition.

\subsection{3.}

Since participation in experiments was voluntary, the number of days between the tests varied individually (alone condition 
first series: $\bar{X} \pm$ S.D. $=9 \pm 3$; alone condition second series and dyadic condition: $\bar{X} \pm$ S.D. $=4 \pm 0.33$ ). The number of tested individuals varied between conditions. Of the 13 hand-raised ravens, 12 individuals were tested in the alone condition. One juvenile female was excluded from all experiments since she was ill during the nestling period and showed retarded development. She was kept together with a juvenile male in a separate aviary. Hence, we performed the dyadic tests with only 11 birds. We combined each of 11 juveniles with every other bird resulting in 55 dyadic combinations. Testing order was semi-randomised: the first two ravens entering the test compartment were used as subjects unless they had been tested together before.

In either condition, alone and dyadic, once the bird(s) to be tested were separated, the experimenter (M.S.) put the novel object(s) in place and observed the behaviour of the subject(s) for $20 \mathrm{~min}$. The novel objects were positioned in the centre of the aviary compartment to allow the birds to approach the novel objects from all sides. Due to structures in the aviary (stones, tree trunks), the central part of the aviary compartment was not fully visible from outside the aviary. Hence, in all conditions M.S. took the data from one position inside the aviary. All birds were well habituated to people, including the experimenter, collecting data inside the aviary, as this was a standard procedure of data collection since the birds fledged. Thus, it is unlikely that the experimenters' presence in the aviary did affect the ravens' approach to the novel objects.

In total, we offered 8 different objects in the alone condition (4 in each series) and 15 in the pair condition (bottles, boxes, soft toys, gloves, shoes, cups, etc., in a size range of $25-45 \mathrm{~cm}$ lengths). We tested all individuals with the same novel objects, but each object was presented only once per bird and the sequence was the same for all birds. Each bird was tested only once per day. In the dyadic tests, we offered two equal novel objects $(1.5 \mathrm{~m}$ apart from each other) to match the number of novel objects with the number of birds in the test. Pilot experiments with other ravens showed that $20 \mathrm{~min}$ are appropriate to observe exploratory behaviour and social interactions. The latter occur mainly after ravens lose their initial interest in the novel objects. In fact, birds showed socio-positive behaviours mainly after approach and exploration of the novel objects: approach frequency peaked in the first minute of the trials, whereas the peaked in minute 19 or in the 19 th minute. The ravens spent significantly more time sitting close to each other from minute 11 to 20 of the trials than from minute 1 to 10 (Wilcoxon: $n=11$, $z=-2.40, P=0.016)$. Agonistic interactions were rare during the tests ( 55 threats in 55 trials, most of them occurring during the first $4 \mathrm{~min}$ ).

\subsection{Data collection}

For each individual, we measured approach latency (in seconds, distance to the novel object $<1 \mathrm{~m}$ ), approach frequency and time spent close $(<1 \mathrm{~m})$ to the novel object (in seconds) as well as the duration of novel object manipulation (in seconds). In the dyadic condition we also noted agonistic interactions: the number of threats and retreats. The duration (in seconds) of sitting in proximity (distance between the birds $<0.5 \mathrm{~m}$ ) was recorded as socio-positive interaction. We defined as joint approach when one individual followed the other approaching a novel object (distance between the birds < approximately one body length).

We used the duration that two birds sat close to each other during the $20 \mathrm{~min}$ test period to define the quality of their social relationship. The obtained classification correlated with the one from daily observations that were conducted in parallel to the experiments. The correlation coefficient was rather low, however (Spearman rank correlation: $r_{\mathrm{s}}=0.51, N=55, P<0.001 ; N$ is the number of dyadic combinations), which is probably due to the higher number of potential partners when the whole group is together. Since agonistic interactions hardly ever occurred during the novel object tests, we calculated dominance rank on the basis of approach-retreat interactions observed during daily protocols. The data were collected by C. Schloegl and M.-C. Loretto (inter-observer reliability test: Cohen's kappa: 0.81). The probability that the observed linearity $\left(h^{\prime}=0.79\right)$ resulted from a random process was $P<0.001$ (MatMan, 1998). All but one male outranked all females.

\subsection{Analysis}

For comparison between alone and dyadic condition, we only used data of the second series of novel objects tests, in order to compare birds of the same developmental period. Since individuals not always approached or manipulated the novel objects during the $20 \mathrm{~min}$ test period, we calculated latencyscores instead of using exact latency times. This way we avoided cutting the distribution of latency times at the upper end (by accepting $20 \mathrm{~min}$ in case the individuals did not approach the novel objects). The number of trials with approach was divided by the sum of latencies of all trials (=sum of latency times when the birds approached plus 20 min for each trial the birds did not approach; Theobald and Goupillot, 1990). However, calculating latency scores was not feasible when comparing sibling and non-sibling combinations, because the number of siblings differed between individuals and therefore the number of trials with potential approach to the novel objects (which is used as a correction factor, see above) was not the same for all individuals. Instead, we calculated mean latencies when comparing sibling with non-sibling combinations. Whenever birds did not approach the novel object, we scored 20 min as latency. Since males were higher ranking than the females we statistically controlled for the effect of sex, when analysing effects of rank. Data were analysed using the software package SPSS (Version 9.0.1, 1999), MatMan (Noldus, Version 1.0, 1998) or calculated by hand according to Lamprecht (1999, Chi-square test) and Siegel and Castellan (1988). Only nonparametric tests were used. Test results are given two-tailed. $0.1>$ alpha $>0.05$ we considered as trends. Because the usefulness of alpha corrections in case of a low sample size seems questionable (Nakagawa, 2004), we present the original $P$ values. We mention the maximum $P$-value possible in each case to still reach a significance level of alpha $<0.05$ after Bonferroni correction. 


\section{Results}

\subsection{Alone condition: consistency in approach and exploratory behaviour over development}

Individuals' latency scores to approach novel objects in the first series correlated with the latency scores in the second series (Spearman rank correlation: $r_{\mathrm{s}}=0.65, N=12, P=0.023$ ), as did the duration of object manipulation (Spearman rank correlation: $\left.r_{\mathrm{s}}=0.75, N=12, P=0.005\right)$, showing that individual responses remained consistent over the two test series. The duration birds stayed close to the novel objects tended to correlate between test series (Spearman rank correlation: $r_{\mathrm{s}}=0.51, N=12, P=0.089$ ).

Still, we observed some age effect: at six months of age (series 2), ravens spent significantly more time close to the novel objects (Wilcoxon signed-ranks test: $T^{+}=77, N=12$, $P=0.001$; Fig. 1) than at three months of age (series 1 ). However, there was no difference in the duration of object manipulation (Wilcoxon signed-ranks test: $T^{+}=42, N=12, P=0.85$ ) between the two test series. Birds spent a similar amount of time close to the different novel objects at three months of age (series 1, Friedman test: $\chi^{2}=1.99$, d.f. $=3, P=0.57$ ), whereas at six months of age (series 2), they showed a distinct serial effect, spending significantly more time close to the first object as compared to the following three (Friedman test: $\chi^{2}=11.97$, d.f. $=3, P=0.007$; Wilcoxon signed-ranks test post hoc $-N=12$, object $1-2: Z=-2.40, P=0.017$, object $1-3$ : $Z=-2.05, P=0.041$, object $1-4: Z=-2.85, P=0.004$, object 2-3: $Z=-0.22, P=0.83$, object $2-4: Z=-2.67, P=0.008$, object 3-4: $Z=-0.80, P=0.42 ; P<0.008$ remain significant after Bonferroni correction, $P<0.05$; Fig. 1).

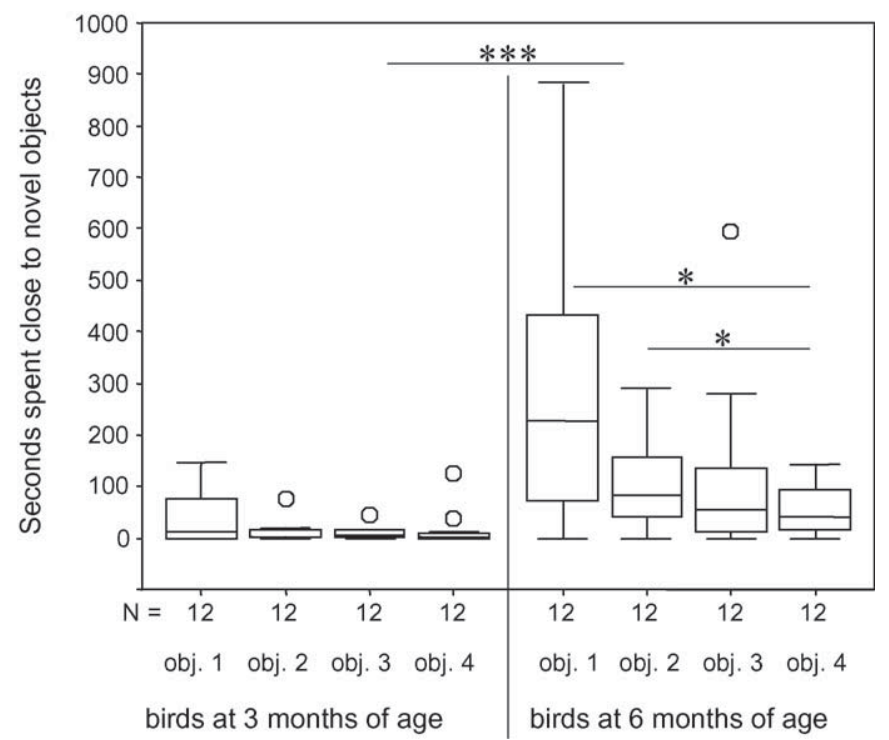

Fig. 1. Time (seconds) spent close (within $1 \mathrm{~m}$ ) to the novel objects when tested at three and six months of age in the alone condition. $N$ : number of birds tested. Box plots show the median and the interquartile range from the 25th to the 75 th percentile. Whiskers indicate the 10th and the 90th percentiles. Circles visualise out-layers. Asterisks mark results of Wilcoxon signed-ranks test $\left({ }^{* * *} P<0.001\right)$, Friedman test and Wilcoxon signed-ranks test, post hoc tests Bonferroni corrected of between object test differences $\left({ }^{*} P<0.05\right)$.
There were significant differences between individuals in the amount of time they spent close to and were manipulating novel objects at six months of age (Kruskal-Wallis test: time spent close to novel objects: $\chi_{11}^{2}=27.51, P=0.004$; duration of object manipulation: $\left.\chi_{11}^{2}=26.90, P=0.005\right)$ but not at three months of age (Kruskal-Wallis test: time spent close to novel objects: $\chi_{11}^{2}=16.17, P=0.13$, duration of object manipulation: $\chi_{11}^{2}=$ $10.55, P=0.44)$.

We did not observe differences between the sexes (Mann-Whitney $U$-test $-N=12$, latency to approach: series $1, Z=-1.38, P=0.17$; series $2, Z=-0.49, P=0.63$; time spent close to novel objects: series $1, Z=-1.14, P=0.25$; series $2, Z=-0.57, P=0.57$; duration of novel object manipulation: series $1, Z=-1.46, P=0.25$; series $2, Z=-0.57$, $P=0.57$ ), nor did rank correlate with approach behaviour (series $2, N=12$, latency to approach: partial correlation coefficient $=0.21$, d.f. $=8, P=0.57$; time spent close: partial correlation coefficient $=0.24$, d.f. $=8, P=0.51$ ).

\subsection{Effects of social context: comparison between the alone condition and the dyadic condition}

Individuals generally approached the novel objects faster when tested alone than when with a conspecific (Wilcoxon signed-ranks test: $T^{+}=64, N=11, P=0.003$ ). The approach latency and the time birds spent close to the novel objects was positively correlated between conditions, alone and in dyads, indicating that individuals remained consistent in their approach behaviour over contexts (Spearman rank correlation: $N=11$, latency to approach: $r_{\mathrm{S}}=0.63, P=0.040$; time spent close: $\left.r_{\mathrm{s}}=0.66, P=0.026\right)$. Individuals differed in the time they spent close to the different novel objects. In the first two trials they spent less time close to the novel objects than in the following eight trials (Friedman test: $\chi^{2}=17.84$, d.f. $=9$, $P=0.037$; Wilcoxon signed-ranks test, post hoc, for between object comparison, no significant differences after Bonferroni correction)

\subsection{Effects of social relationships}

In sibling dyads, ravens spent significantly more time sitting close $(<50 \mathrm{~cm})$ to each other than in non-sibling combinations (Wilcoxon signed-ranks test: $T^{+}=51, N=10, P=0.014$ ). Individuals' mean approach latency in the alone condition did not significantly differ from the latency when tested in sibling dyads (Wilcoxon signed-ranks test: $T^{+}=33, N=10, P=0.62$ ). When in non-sibling dyads, birds tended to approach the novel objects later than when alone (Wilcoxon signed-ranks test: $T^{+}=55$, $N=11, P=0.052$ ). Moreover, ravens followed a sibling significantly faster during the first approach than a non-sibling (Wilcoxon signed-ranks test: $T^{+}=36, N=8, P=0.008, N=8$ because two birds were always first to approach when with a sibling), but did not spend more time close to (Wilcoxon signed-ranks test: $T^{+}=35, N=10, P=0.49$ ) or manipulating (Wilcoxon signed-ranks test: $T^{+}=42, N=10, P=0.16$ ) the novel objects. 


\subsection{Differences between the sexes}

Despite the lack of differences between the sexes in approach behaviour when tested alone, males approached the novel objects significantly faster than females in the dyadic condition (Mann-Whitney $U$-test: $W_{x}=16, W_{y}=45, N_{1 \text { females }}=5$, $\left.N_{2 \text { males }}=6, P=0.004\right)$. Males tended to spend more time close to the novel objects (Mann-Whitney $U$-test: $W_{x}=22$, $W_{y}=44, N_{1 \text { females }}=5, N_{2}$ males $\left.=6, P=0.089\right)$ and manipulated them significantly longer (Mann-Whitney $U$-test: $W_{x}=19$, $\left.W_{y}=47, N_{1 \text { females }}=5, N_{2 \text { males }}=6, P=0.026\right)$ as compared to the females. In addition, males joined their conspecifics significantly more often to approach novel objects than females did (Mann-Whitney $U$-test: $W_{x}=21.5, W_{y}=44.5, N_{1 \text { females }}=5$, $N_{2 \text { males }}=6, P=0.044$ ).

Concerning the very first approach to novel objects per dyad, in male-male combinations, subordinate individuals were more often first to stay close to the novel objects than dominants (Chi-square test: $\chi_{14}^{2}=6.93, P<0.01$ ). In contrast, in male-female combinations, males approached the novel objects significantly more often first than females (Chi-square test: $\left.\chi_{29}^{2}=12.17, P<0.001\right)$. All, but one male were dominant over the females. There was no difference in female-female combinations in how often dominant or subordinate individuals approached the novel objects first (Chi-square test: $\chi_{8}^{2}=0.44$, $P>0.5$, in one dyad none of the females approached the novel objects; Fig. 2). Both, males and females approached the novel objects for the first time later in mixed-sex combinations than in same-sex combinations (mean approach latency: males in male-male dyads versus male-female dyads, Wilcoxon signedranks test: $T^{+}=21, N=6, P=0.03$; females in female-female dyads versus male-female dyads, Wilcoxon signed-ranks test: $\left.T^{+}=15, N=5, P=0.062\right)$. There was no difference between same-sex and mixed-sex combinations in time spent close to the novel objects (mean duration: males in male-male dyads versus male-female dyads, Wilcoxon signed-ranks test: $T^{+}=18, N=6, P=0.16$; females in female-female dyads versus male-female dyads, Wilcoxon signed-ranks test: $T^{+}=11$, $N=5, P=0.43$ ) nor in the time the birds spent sitting in proximity to one another (mean duration: males in male-male dyads versus male-female dyads, Wilcoxon signed-ranks test: $T^{+}=18, N=6, P=0.16$; females in female-female dyads versus

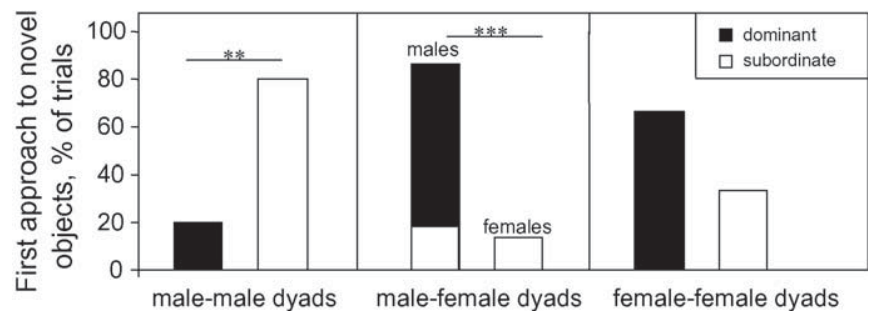

Fig. 2. Percentage of trials dominants or subordinates were the first ones to approach the novel objects. We distinguished between male-male $(N=15)$, male-female $(N=30)$ and female-female $(N=10)$ dyads. Asterisks mark results of Chi-square tests between number of first approaches by dominants and subordinates $\left({ }^{* * *} P<0.001\right.$ and $\left.{ }^{* *} P<0.01\right)$. Black bars indicate the approaches of dominants and white bars indicate the approaches of subordinates. male-female dyads, Wilcoxon signed-ranks test: $T^{+}=14, N=5$, $P=0.12$ ).

\section{Discussion}

In accordance with biological personality theory (Wilson et al., 1994; Koolhaas et al., 1999) we found that individuals showed consistency in exploratory behaviour over the considered developmental period and across contexts. In respect to approaching novel objects individuals remained fast or slow in relation to the others, rather than being always equally fast or slow. Contrary to great tits (Carere et al., 2005), all ravens were faster with six months of age than with three months of age, not only the initially slow individuals as it was the case in the great tits.

Birds, at six month of age spent significantly more time close to the first novel object in the alone condition, than to the subsequent three novel objects (Fig. 1). This serial effect could have been due to object features, such that the first novel object was somehow more attractive for the ravens (object order was the same for all birds) than the following three. The ravens could also have lost interest due to the repetition, even though objects were always new. Menzel and Menzel (1979) showed habituation to novelty (repeated presentation of novel objects in the aviary) in marmosets, Saguinus fuscicollis. Ravens quickly stop participating in experiments when tests are repeated frequently (own observation). In the dyadic condition serial effects may have been less pronounced and overshadowed by effects related to the dyad composition, which differed between the tests.

Individuals approached the novel objects faster when tested alone compared to when with a conspecific. This may have been due to socially influenced neophobia being a contagion of fear rather than a contagion of fearlessness. Also, in the dyadic condition one bird could have waited for the other one to take the potential risk to approach first. Hence, not only the individuals' neophobia per se, but also the birds' willingness to take the risk of the first approach may have affected their behaviour. In fact, dominant males approached the novel objects first when in a dyad with a female, but not when with a male. Despite a delayed initial approach, social context had facilitating effects on novel object exploration: birds spent more time close to and manipulating the novel objects when tested in dyads or as a group (Stöwe et al., in press) compared to when alone.

The companion with whom the birds were tested might notably have affected their behaviour. It has been shown, for example, that observing more experienced, dominant and attractive models may facilitate learning on the side of observers (Nicol and Pope, 1994; Benskin et al., 2002; but see Beauchamp and Kacelnik, 1991; Swaney et al., 2001). In the ravens, we observed pronounced differences between sibling and nonsibling dyads. Only when in a dyad with a non-sibling, the initial approach to novel objects tended to be delayed compared to the alone condition. Once the ravens approached the novel objects, they spent more time close to and manipulating the novel objects in the dyadic condition than in the alone condition, no matter if they were with a sibling or with a non-sibling. Comparing sibling to non-sibling dyads, birds followed siblings faster to approach 
the novel objects than non-siblings. In addition, siblings spent more time sitting close to each other than non-siblings. In species living in social groups, kin often spend more time close together, tolerate smaller inter-individual distances and are more prone to share food than non-kin (e.g. Hohmann et al., 1999; Brown et al., 2004). This increases the possibility and probability of socially facilitated behaviours and social learning (e.g. Heyes and Galef, 1996; Fritz et al., 2000; Fragaszy and Visalberghi, 2004). In our experiments, the possibility to initially approach the novel objects was not limited due to one bird monopolising the access to the novel objects, since the distance between the objects was too big. Thus, the conditions to approach and explore the novel objects were equal for sibling and non-sibling combinations.

At the time we conducted the dyadic tests, young freeranging ravens would have joined non-breeder groups after becoming independent from their parents. Scavenging ravens frequently encounter novel situations and novel food sources (Heinrich, 1988b). For young and inexperienced birds any facilitation while searching for food is potentially advantageous. In fact, Webb (2001) observed, that free-ranging juvenile ravens spent significantly more time close to their siblings than to nonsiblings. Even if being close to another relatively inexperienced conspecific may be less advantageous than being close to an experienced bird, it might still facilitate the approach to novel objects/potential food sources and thus increase exploration.

Greenberg and Mettke-Hofmann (2001) hypothesised that if pay-offs are asymmetrical and the rank hierarchy is linear, subordinates should take the risk to approach novel objects first. This, in fact has been observed in several studies (e.g. Katzir, 1982; Gómez-Laplaza, 2002). In our experiments, this was only true for the male-male combinations but not for female-female dyads. Most interestingly, in female-male combinations, males were significantly more often the first ones to approach the novel objects, even though in all but one case, males were higher ranking than females. Thus, the sex of the conspecific had a major influence on whether the dominant or the subordinate was first to approach the novel objects. In addition, males joined their conspecifics significantly more often to approach novel objects and manipulated the objects significantly longer in the dyadic condition than females did. These differences between the sexes in latency to approach and exploratory behaviour when tested in dyads support the idea that males used the opportunity to show off. Also, in non-breeder groups of free-ranging ravens males seem to be more prone to take risks. In wild ravens co-feeding with wolves at the local Cumberland game park, more young males were killed by the wolves than females (of 12 killed ravens 9 were male and only 3 were females; Bugnyar and Kotrschal, unpublished).

In great tits, females showed longer latencies to return to a feeding table after a startle when tested in a social context than males (van Oers et al., 2005). In our study, individuals of both sexes were similarly affected by the presence of a conspecific. In the great tits, focal animals were combined with unfamiliar adult males that might have affected females differently than males. In fact, in the ravens, both sexes approached the novel objects significantly later when tested in mixed-sex dyads as compared to when in same-sex dyads, even though birds were the same age and were familiar with each other. Hence, in mixed-sex combinations, factors such as showing off, attraction and affiliation influenced the behaviour of the birds. We did not observe any difference in socio-positive behaviours (duration of sitting in close proximity), between same-sex and mixed-sex dyads during the tests. This might be due to the fact that the ravens were not sexually mature when tested and showed high rates of sociopositive behaviours towards both, same-sex and opposite-sex conspecifics.

To conclude, individuals remained consistent in their exploratory behaviour over the developmental period observed. Whether social context had facilitating or delaying effects depended on the relatedness/social relationship among the companions and the combination of the sexes. Contributions of these factors may explain ambiguous results concerning facilitating or inhibitory effects due to social context in previous studies.

\section{Acknowledgements}

We acknowledge the FWF for the research grants for M. Stöwe (P16939 B03) and T. Bugnyar (E. Schrödinger J2064, 2225). Permanent support was provided by the Verein der Förderer der Konrad Lorenz Forschungsstelle and the Herzog von Cumberland Stiftung. We thank the zoos of Munich and Wuppertal (Germany) and P. Sömmer for the supply with raven nestlings. Raven nestlings from the wild were taken with permit by the Ministerium für Landwitschaft, Umweltschutz und Raumordnung des Landes Brandenburg. We thank two anonymous referees for constructive comments on an earlier draft of the manuscript.

\section{References}

Armitage, B.A., 1986. Individuality, social behaviour and reproductive success in yellow-bellied marmots. Ecology 67, 1186-1193.

Barnard, C.J., Sibly, R.M., 1981. Producers and scroungers: a general model and its application to captive flocks of house sparrows. Anim. Behav. 29, 543-550.

Beauchamp, G., Kacelnik, A., 1991. Effects of knowledge of partners on learning rates in zebra finches Taeniopygia gattata. Anim. Behav. 41, 247-253.

Benskin, C., Mc, W.H., Mann, N.I., Lachlan, R.F., Slater, P.J.B., 2002. Social learning directs feeding preferences in the zebra finch, Taeniopygia guttata. Anim. Behav. 64, 823-828.

Both, C., Dingemanse, N.J., Drent, P.J., Tinbergen, J.M., 2005. Pairs of extreme avian personalities have highest reproductive success. J. Anim. Ecol. 74, 667-674.

Brown, C., Laland, K., 2001. Social learning and life skills training for hatchery reared fish. J. Fish Biol. 59, 471-493.

Brown, C., Laland, K., 2002. Social enhancement and social inhibition of foraging behaviour in hatchery reared Atlantic salmon. J. Fish Biol. 61, 987-998.

Brown, G.R., Almond, R.E.A., van Bergen, Y., 2004. Begging, stealing, and offering: food transfer in nonhuman primates. Adv. Stud. Behav. 34, 265-295.

Bugnyar, T., Kotrschal, K., 2001. Movement coordination and signalling in ravens (Corvus corax): an experimental field study. Acta Ethol. 3, 101-109.

Bugnyar, T., Kijne, M., Kotrschal, K., 2001. Food calling in ravens: are yells referential signals? Anim. Behav. 61, 949-958. 
Caldwell, C.A., Whiten, A., 2003. Scrounging facilitates social learning in common marmosets, Callithrix jacchus. Anim. Behav. 65, 1085-1092.

Carere, C., Welink, D., Drent, P.J., Koolhaas, J.M., Groothuis, T.G.G., 2001 Effects of social defeat in a territorial bird (Parus major) selected for different coping styles. Physiol. Behav. 73, 427-433.

Carere, C., Groothuis, T.G.G., Möstl, E., Dann, S., Koolhaas, J.M., 2003 Fecal corticosteroids in a territorial bird selected for different personalities: daily rhythm and the response to social stress. Horm. Behav. 43, 540-548.

Carere, C., Drent, P.J., Privitera, L., Koolhaas, J.M., Groothuis, T.G.G., 2005 Personalities in great tits (Parus major): stability and consistency. Anim. Behav. 70, 795-805.

Cavigelli, S.A., McClintock, M.K., 2003. Fear of novelty in infant rats predicts adult corticosterone dynamics and an early death. PNAS 100 (26) $16131-16136$

Coleman, S.L., Mellgren, R.L., 1994. Neophobia when feeding alone or in flocks in zebra finches, Taeniopygia guttata. Anim. Behav. 48, 903-907.

Coleman, K., Wilson, D.S., 1998. Shyness and boldness in pumkinseed sunfish: individual differences are context specific. Anim. Behav. 56, 927-936.

Daisley, J.N., Bromundt, V., Möstl, E., Kotrschal, K., 2004. Enhanced yolk testosterone influences phenotype independent of sex in Japanese quail chicks Coturnix japonica. Horm. Behav. 47, 185-194.

Dingemanse, N.J., de Goede, P., 2004. The relation between dominance and exploratory behaviour is context-dependent in wild great tits. Behav. Ecol. 15 (6), 1023-1030.

Dingemanse, N.J., Both, C., Drent, P.J., van Oers, K., van Noordwijk, A.J., 2002. Repeatability and heritability of exploratory behaviour in great tits from the wild. Anim. Behav. 64, 929-937.

Dingemanse, N.J., Both, C., van Noordwijk, A.J., Rutten, A.L., Drent, P.J., 2003. Natal dispersal and personalities in great tits (Parus major). Proc. R. Soc. Lond. B 270, 741-747.

Dingemanse, N.J., Both, C., Drent, P.J., Tinbergen, J.M., 2004. Fitness consequences of avian personalities in a fluctuating environment. Proc. R. Soc. Lond. B 271, 847-852.

Drent, P.J., Marchetti, C., 1999. Individuality, exploration and foraging in hand raised juvenile great tits. In: Adams, N.J., Slotow, R.H. (Eds.), Proceedings of the 22 International Ornithology Congress. Birdlife South Africa, Durban, Johannesburg, pp. 896-914.

Drent, P.J., van Oers, K., van Noordwijk, A.J., 2003. Realised heritability of personalities in the great tit (Parus major). Proc. R. Soc. Lond. B 270, 45-51.

Forkman, B., 1991. Social facilitation is shown by gerbils when presented with novel but not with familiar food. Anim. Behav. 42, 860-861.

Fragaszy, D.M., Visalberghi, E., 1996. Social learning in monkeys: primate "primacy" reconsidered. In: Heyes, C.M., Galef Jr., B.G. (Eds.), Social Learning in Animals, the Roots of Culture. Academic Press, San Diego, pp. $65-84$.

Fragaszy, D.M., Visalberghi, E., 2004. Socially biased learning in monkeys. Learn. Behav. 32, 24-35.

Fritz, J., Kotrschal, K., 1999. Social learning in common ravens, Corvus corax. Anim. Behav. 57, 785-793.

Fritz, J., Kotrschal, K., 2002. On avian imitation: cognitive and ethological perspectives. In: Dautenhahn, K., Nehaniv, C.L. (Eds.), Imitation in Animals and Artefacts. MIT Press, Massachusetts, pp. 133-157.

Fritz, J., Bisenberger, A., Kotrschal, K., 2000. Stimulus enhancement in greylag geese: socially mediated learning of an operant task. Anim. Behav. 59, 1119-1125.

Galef Jr., B.G., 1996. Social enhancement of food preferences in Norway rats: a brief review. In: Heyes, C.M., Galef Jr., B.G. (Eds.), Social Learning in Animals, the Roots of Culture. Academic Press, San Diego, pp. 49-64.

Galef Jr., B.G., Whiskin, E.E., 2000. Social exploitation of intermittently available foods and the social reinstatement of food preference. Anim. Behav. 60, 611-615.

Giraldeau, L.A., Lefebvre, L., 1987. Scrounging prevents cultural transmission of food-finding behaviour in pigeons. Anim. Behav. 35, 387-394.

Glutz von Blotzheim, U.N., Bauer, K.M., 1993. Handbuch der Vögel Mitteleuropas. Band 13/III, Passeriformes (4.Teil), Aula/Wiesbaden, p. 2018.
Gómez-Laplaza, L.M., 2002. Social status and investigatory behaviour in the angelfish (Pterophyllum scalare). Behaviour 139, 1469-1490.

Greenberg, R., 2003. The role of neophobia and neophilia in the development of innovative behaviour of birds. In: Reader, S.M., Laland, K.N. (Eds.), Animal Innovation. Oxford University Press, pp. 175-197.

Greenberg, R., Mettke-Hofmann, C., 2001. Ecological aspects of neophobia and neophilia in birds. Curr. Ornithol. 16, 119-169.

Groothuis, T.G.G., Carere, C., 2005. Avian personalities: characterization and epigenesis. Neurosc. Biobehav. Rev. 29, 137-150.

Heinrich, B., 1988a. Why do ravens fear their food? Condor 90, 950-952.

Heinrich, B., 1988b. Winter foraging at carcasses by three sympatric corvids, with emphasis on recruitment by the raven (Corvus corax). Behav. Ecol. Sociobiol. 23, 141-156.

Heinrich, B., 1994. Does the early raven get (and show) the meat? Auk 111, 764-769.

Heinrich, B., 1995. Neophilia and exploration in juvenile common ravens, Corvus corax. Anim. Behav. 50, 695-704.

Heinrich, B., Marzluff, J.M., 1991. Do common ravens yell because they want to attract others? Behav. Ecol. Sociobiol. 28, 13-22.

Heinrich, B., Marzluff, J.M., 1995. Why ravens share? Am. Sci. 83, 342-350.

Heinrich, B., Marzluff, J.M., Adams, W., 1995. Fear and food recognition in naive common ravens. Auk 112, 499-503.

Heyes, C.M., Galef Jr., B.G., 1996. Social Learning in Animals, the Roots of Culture. Academic Press, San Diego.

Hohmann, G., Gerloff, U., Tautz, D., Fruth, B., 1999. Social bonds and genetic ties: kinship, association and affiliation in a community of bonobos (Pan Paniscus). Behaviour 136, 1219-1235.

Huber, L., Rechberger, S., Taborsky, M., 2001. Social learning affects object exploration and manipulation in keas, Nestor notabilis. Anim. Behav. 62 945-954.

Katzir, G., 1982. Relationships between social structure and response to novelty in captive jackdaws, Corvus monedula L., I. Response to novel space? Behaviour 82, 231-263.

Katzir, G., 1983. Relationships between social structure and response to novelty in captive jackdaws, Corvus monedula L., II. Response to novel palatable food? Behaviour 86, 183-208.

Kijne, M., Kotrschal, K., 2002. Neophobia affects choice of food item size in group foraging common ravens (Corvus corax). Acta Ethol. 5, 13-18.

Koolhaas, J.M., Korte, S.M., de Boer, S.F., van der Vegt, B.J., van Reenen, C.G., Hopster, H., de Jong, I.C., Ruis, M.A.W., Blokhuis, J.H., 1999. Coping styles in animals: current status in behaviour and stress-physiology. Neurosc. Biobehav. Rev. 23, 925-935.

Kotrschal, K., Bugnyar, T., Stöwe, M., 2001. Kognition und Neophobie bei Raben. Charandrius 3, 127-135.

Lamprecht, J., 1999. Biologische Forschung: von der Planung bis zur Publikation. Filander, Fürth.

Marchetti, C., Drent, P.J., 2000. Individual differences in the use of social information in foraging by captive great tits. Anim. Behav. 60, 131140.

Marzluff, J.M., Heinrich, B., 1991. Foraging by common ravens in the presence and absence of territory holders: an experimental analysis of social foraging. Anim. Behav. 42, 755-770.

Marzluff, J.M., Heinrich, B., Marzluff, C.S., 1996. Raven roosts as mobile information centers. Anim. Behav. 51, 83-103.

MatMan, 1998. Noldus Information Technology, Version 1.0 for Windows.

Mason, J.R., Reidinger Jr., R.F., 1981. Effects of social facilitation and observational learning on feeding behaviour of the red-winged blackbird (Agelaius phoeniceus). Auk 98, 778-784.

Menzel Jr., E.W., Menzel, C.R., 1979. Cognitive, developmental and social aspects of responsiveness to novel objects in a family group of marmosets (Saguinus fuscicollis). Behaviour 70, 251-279.

Midford, P.E., Hailman, J.P., Woolfenden, G.E., 2000. Social learning of a novel foraging patch in families of free-living Florida scrub-jays. Anim. Behav. 59, 1199-1207.

Nakagawa, S., 2004. A farewell to Bonferroni: the problems of low statistical power and publication bias. Behav. Ecol. 15, 1044-1045.

Nicol, C.J., Pope, S.J., 1994. Social learning in small flocks of laying hens Anim. Behav. 47, 1289-1296. 
Nicol, C.J., Pope, S.J., 1999. The effects of demonstrator social status and prior foraging success on social learning in laying hens. Anim. Behav. 57, 163-171.

Promberger, C., 1992. Mitteilungen aus der Wildforschung: Wölfe und Raben im Yukon. Der Oberösterreichische Jäger 56, 34-35.

Ratcliffe, D., 1997. The Raven. Academic Press Inc., San Diego.

Reader, S.M., Laland, K.N. (Eds.), 2003. Animal Innovation. Oxford University Press, pp. 3-39.

Ryer, C.H., Olla, B.L., 1991. Information transfer and the facilitation and inhibition of feeding in a schooling fish. Environ. Biol. Fishes 3, 317-323.

Seferta, A., Guay, P.J., Marzinotto, E., Lefebvre, L., 2001. Learning differences between Feral Pigeons and Zenaida Doves: the role of neophobia and human proximity. Ethology 107, 281-293.

Siegel, S., Castellan Jr., N.J., 1988. Nonparametric Statistics for the Behavioural Sciences, second ed. McGraw-Hill, Singapore.

Sih, A., Bell, A., Johnson, C., 2004. Behavioural syndromes: an ecological and evolutionary overview. TREE 19, 372-378.

SPSS, 1999. SPSS for Windows, Version 9.0.1. SPSS, Inc.

Stahler, D., Heinrich, B., Smith, D., 2002. Common ravens, Corvus corax, preferentially associate with grey wolves, Canis lupus, as a foraging strategy in winter. Anim. Behav. 64, 283-290.

Stöwe, M., Bugnyar, T., Heinrich, B., Kotrschal, K. Effects of group size on approach to novel objects in ravens (Corvus corax). Ethology, in press.

Swaney, W., Kendal, J., Capon, H., Brown, C., Laland, K., 2001. Familiarity facilitates social learning of foraging behaviour in the guppy. Anim. Behav. 62, 591-598.

Theobald, C.M., Goupillot, R.P., 1990. The analysis of repeated latency measures in behavioural studies. Anim. Behav. 40, 484-490.

Valsecchi, P., Bosellini, H., Sabatini, F., Mainardi, M., Fiorito, G., 2002. Behavioural analysis of social effects on problem-solving ability in the house mouse. Ethology 108, 1115-1134. van Oers, K., Drent, P.J., de Goede, P., van Noordwijk, A.J., 2004. Realized heritability and repeatability of risk-taking behaviour in relation to avian personalities. Proc. R. Soc. Lond. B 271, 65-73.

van Oers, K., Klunder, M., Drent, P.J., 2005. Context dependence of personalities: risk-taking behaviour in a social and non-social situation. Behav. Ecol. 16, 716-723.

Verbeek, M.E.M., Drent, P.J., Wiepkema, P.R., 1994. Consistent individual differences in early exploratory behaviour of male great tits. Anim. Behav. 48, 1113-1121.

Verbeek, M.E.M., Bonn, A., Drent, P., 1996. Exploration, aggressive behaviour and dominance in pair-wise confrontations of juvenile male great tits. Behaviour 133, 945-963.

Visalberghi, E., Fragaszy, D., 1995. The behaviour of capuchin monkeys, Cebus apella, with novel food: the role of social context. Anim. Behav. 49, 1089-1095.

Visalberghi, E., Addessi, E., 2000. Seeing group members eating a familiar food enhances the acceptance of novel foods in capuchin monkeys. Anim. Behav. 60, 69-76.

Visalberghi, E., Addessi, E., 2003. Social learning about food in capuchin monkeys. In: Fragaszy, D.M., Perry, S. (Eds.), The Biology of Traditions, Models and Evidence. Cambridge University Press, Cambridge, pp. 187-212.

von Holst, D., 1998. The concept of stress and its relevance for animal behaviour. Adv. Stud. Behav. 27, 1-131.

Webb, W.C., 2001. Common raven juvenile survival and movements in a human-augmented landscape. Master's Thesis. University of California, Riverside.

Wilson, D.S., Clark, A.B., Coleman, K., Dearstyne, T., 1994. Shyness and boldness in humans and other animals. TREE 9, 442-446. 